\title{
Definition and estimation of osteonecrosis of jaw (ONJ), and optimal duration of antiresorptive treatment in bone metastatic cancer patients: supplementary data from the denosumab extension study?
}

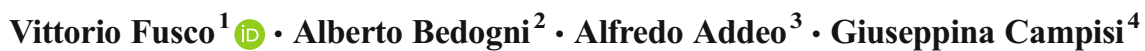

Received: 26 January 2016 / Accepted: 22 February 2016 / Published online: 9 March 2016

(C) Springer-Verlag Berlin Heidelberg 2016

To the Editor,

In their recent article, Stopeck et al. [1] concluded that denosumab confirms its known safety profile even after longterm exposure, or after switching to it from zoledronic acid, and that osteonecrosis of jaws (ONJ) rates increased with increasing exposure to antiresorptives, consistent with previous reports.

This is based on the open label extension phase of two phase 3 studies in patients with breast and prostate cancer with bone metastases who were randomized to receive denosumab or zoledronic acid (ZA) [2, 3]. The patients were offered open-label denosumab for up to an additional 2 years after the results of the primary analysis, favorable for denosumab on several aspects. Patients initially randomized to denosumab (denosumab/ denosumab group) continued to receive denosumab at $120 \mathrm{mg}$ Q4W whereas patients on ZA were switched to denosumab in the open-label phase (ZA/denosumab group) at $120 \mathrm{mg}$ Q4W starting 4 weeks from their last ZA dose. Patients who declined further therapy in the open-label extension phase, or who did not complete the blinded treatment phase, continued follow-up for survival every 12 weeks (Q12W) for up to 2 years after their last dose.

Vittorio Fusco

vittoriofusco1@tin.it

1 Oncology Unit, SS Antonio e Biagio e Cesare Arrigo Hospital, Alessandria, Italy

2 Unit of Maxillofacial Surgery, Department of Neurosciences - DNS, University of Padua, Padua, Italy

3 Bristol Cancer Institute, University Hospitals Bristol NHS, Bristol, UK

4 Department of Surgical, Oncology and Oral Sciences - Sector of Oral Medicine, Palermo University, Palermo, Italy
We collected data from the text and the tables of the paper published by Stopeck et al. [1] and summarized them in a new table (Table 1).

Although authors' conclusions are quite reassuring both in terms of denosumab safety and efficacy, it is noteworthy that the median exposure of patients to denosumab in the extension phase study is lower than expected, even in the presence of a longer range. The final median exposure of the 318 denosumab/denosumab breast cancer patients is 19.1 months (range 0.1-59.8), not much longer than that registered for the whole cohort of the 1019 breast cancer patient population enrolled in the blinded phase, that was 17.6 months (range 0 23.7). As far as prostate cancer patients are concerned, the median denosumab exposure was 12.0 months (range 0.1 67.2) for the 147 denosumab/denosumab patients from the extension study versus 12.0 months (range 0.1-23.3) for the 942 patients enrolled in the original randomized trial. We could not work out from the paper the median denosumab exposure for 318 breast and 147 prostate cancer patients of the extension study denosumab/denosumab population in the previous blinded phase. This appears to us a weakness of the article.

Interestingly, the frequency of ONJ cases in the open label extension study appears substantially higher than what is found in the initial blinded phase (ONJ frequency ranging from 1 to $2 \%$ ) $[2,3]$ despite median denosumab exposure was not significantly longer in the former. The crude ONJ figures increased both in denosumab/denosumab groups and in ZA/denosumab populations: ONJ cases were respectively $20 / 318(6.3 \%)$ in breast patients and $12 / 147(8.2 \%)$ in prostate patients in the denosumab/denosumab group, whereas they were 18/334 (5.4\%) breast patients and 7/118 (5.9\%) prostate patients in the $\mathrm{ZA} /$ denosumab group.

Such an increase in ONJ frequency highlights the need for longer patients' monitoring and the adoption of nonparametric actuarial estimation (Kaplan-Meier), as done in other studies 


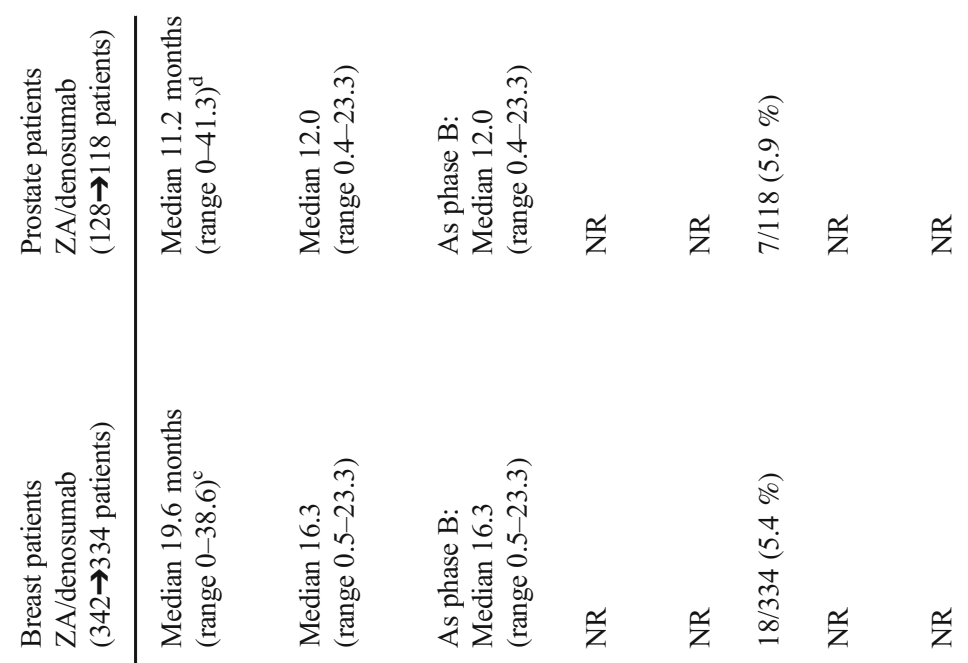

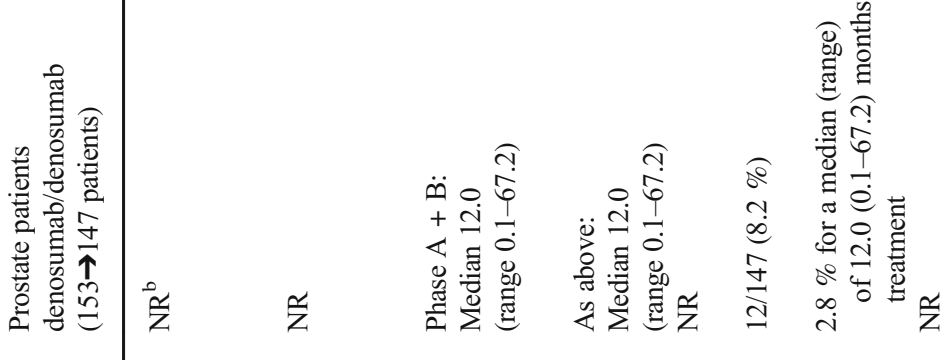

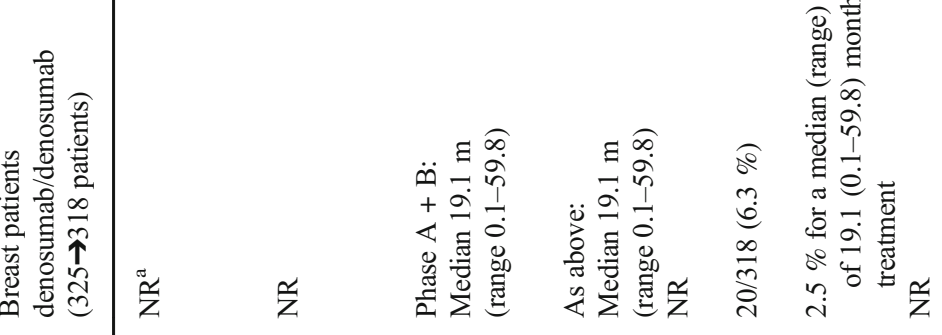

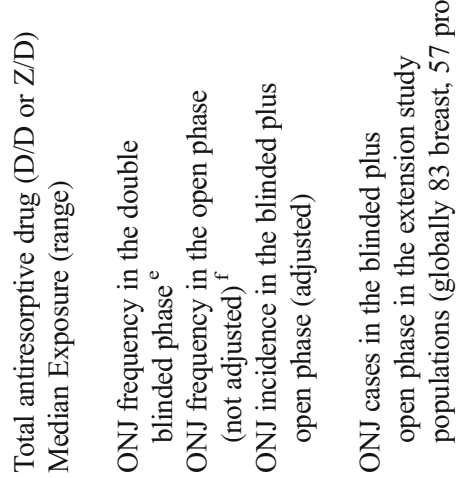

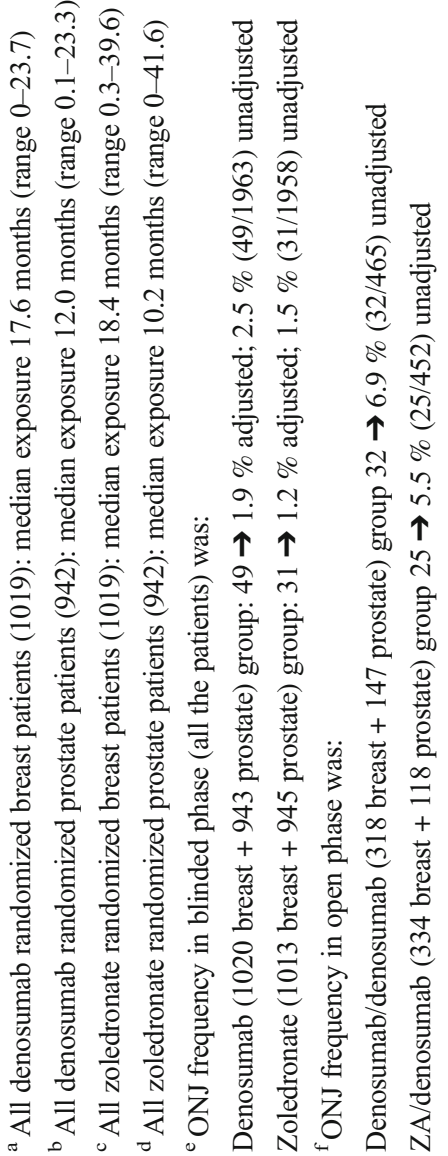


[4-9], to obtain the projected individual ONJ risk at 2, 3, and 4 years of treatment. Separate analysis should be performed by Stopeck et al. [1] for breast and prostate cancer patients, showing these latter ones a similar ONJ rate increase even after shorter median drug exposure.

Saad et al. published in 2012 [10] the integrated analysis of the results of three pivotal trials of blinded comparison between denosumab and zoledronic acid: they also reported the number of "potential ONJ" cases that were initially registered as spontaneously reported by investigators or on the base of 36 MedDRA (Medical Dictionary for Regulatory Activities) adverse oral event terms. "Potential ONJ" cases, defined by the presence of clinical sign and symptoms suggestive of ONJ, were three times higher than the finally "adjudicated ONJ" cases: 276/5723 (4.8\%) versus 89/5723 $(1.5 \%)$. Of importance, such data were recorded after a relatively short observation time, being the median $(\mathrm{Q} 1, \mathrm{Q} 3)$ time on study $12.1(5.4,19.4)$ months for patients in the ZA group and $12.6(5.6,19.4)$ months for patients in the denosumab group [10]. We believe that it would be of great value if the authors of the extension study [1] could report the number of "potential ONJ" cases (defined as above) observed in the breast and prostate cancer population of the extension study, and compare them with those of the blinded study, and those among patients who declined shift to denosumab, if available.

There are two burning aspects that we would like to address: the definition of ONJ and the optimal duration of antiresorptive (bisphosphonates or denosumab) treatment.

The definition of ONJ is highly debated and controversial, with evident consequences on clinical practice, trials, and epidemiological studies. The initial definition of ONJ as proposed and published in 2007 by a Task Force of the American Association of Oral Maxillofacial Surgeons (AAOMS) [11] was based on the presence of exposed bone in the oral cavity lasting at least 8 weeks in patients treated with bisphosphonates who did not receive radiation therapy of the head and neck region. This case definition was adopted to adjudicate ONJ patients in clinical trials on bisphosphonates and denosumab.

In recent years, increasing evidence of symptomatic cases of medication-related jawbone alterations without frank bone exposure has raised skepticism among clinicians who questioned the original BRONJ (Bisphosphonate-Related ONJ) case definition, assuming that it could have contributed to epidemiological estimates being inconsistent because it excluded cases with no obviously exposed bone [12]. In 2009, the AAOMS Task Force updated its recommendations on BRONJ [13] by adding the "stage 0 " to classify patients presenting with a number of oral signs and symptoms other than bone exposure but, unfortunately, they did not modify the 2007 definition. The contradictory nature of the position paper was then underlined by several authors and researchers, claiming for a broader definition to include the "non-exposed" ONJ variant $[14,15]$.
Hence, the AAOMS Task Force released in 2014 a third position paper [16] that partially expanded the definition of disease to include cases with "bone that can be probed through an intraoral or extraoral fistula in the maxillofacial region that has persisted for longer than 8 weeks" and confirmed the existence of a "stage 0 category" for patients with signs and symptoms other than bone exposure and soft-tissue fistulas ("nonspecific symptoms or clinical and radiographic abnormalities that might be due to exposure to an antiresorptive agent") [16]. The original acronym BRONJ (bisphosphonaterelated ONJ) was also implemented to include cases of ONJ that were reported after treatment with antiangiogenic agents and denosumab, so that the terms ONJ and MRONJ (medication-related ONJ) are now more correctly used [16]. The AAOMS experts admitted the risk of underestimation of such a definition based only on two clinical signs (bone exposure and fistula), choosing that risk versus the opposite risk of an eventual overestimation (inducible, according to them, by "cases with radiographic signs alone") [16]. Overall, these long-lasting controversies on definition are still likely to cause incorrect estimation of ONJ incidence in clinical studies, as well as patient selection and a too-short follow-up duration [17]. On the other hand, an overly restricted ONJ definition might result in late diagnosis of $\mathrm{ONJ}$ in clinical practice, exposing patients to rare but life-threatening complications $[18,19]$.

The optimal duration of bone metastatic treatment with antiresorptive drugs (i.e., bisphosphonates and denosumab) is yet to be defined.

Most guidelines recommended the long-lasting administration of antiresorptives (that is, till to deterioration of patient general conditions) based on the substantial lack of demonstrated serious side effects in published trials [20,21]. After reporting several cases of renal toxicity and ONJ, especially in patients exposed for longer time, since years 2006-2007 some guidelines indicated treatment with bisphosphonates for 1 or 2 years, and then "tailoring" the therapy, for both myeloma patients [22-24] and bone metastases of solid tumors [25]. Despite this, the ASCO did not change recommendations for bone metastatic breast cancers till 2011, after approval of denosumab [26]: it was underlined that "There are no prospective clinical RCT data to support the continuation of bone-modifying agent therapy beyond 1 year" whereas in the summary table, at the voice "Optimal duration" it was reported "Unchanged in substance from 2003" (that is "continued until evidence of substantial decline in a patient's general performance status.") [26].

In conclusion, more data on oral discomfort and more follow-up data from the extension study by Stopeck et al. [1] could be of great value to help patients and prescribers of antiresorptive drugs to share a tailored treatment with the most favorable cost-effectiveness, based on sound evaluation of individual risk factors for safety, together with undeniably favorable effects on skeletal-related effects (SRE) and quality of life. 


\section{Compliance with ethical standards}

Disclosures Dr. Fusco has participated in advisory boards on metastatic bone disease (Amgen); he transferred the fee to an advocacy patient group.

Dr. Addeo received expert grant by Bristol-Myers Squibb and Pierre Fabre, and travel and accommodation expenses by Boehringer Ingelheim.

Conflict of interest The remaining authors have stated that they have no conflicts of interest.

\section{References}

1. Stopeck AT, Fizazi K, Body JJ, et al. (2015) Safety of long-term denosumab therapy: results from the open label extension phase of two phase 3 studies in patients with metastatic breast and prostate cancer. Support Care Cancer 24:447-455. doi:10.1007/s00520015-2904-5

2. Stopeck AT, Lipton A, Body JJ, Steger GG, Tonkin K, de Boer RH, Lichinitser M, Fujiwara Y, Yardley DA, Viniegra M, Fan M, Jiang Q, Dansey R, Jun S, Braun A (2010) Denosumab compared with zoledronic acid for the treatment of bone metastases in patients with advanced breast cancer: a randomized, double-blind study. J Clin Oncol 28:5132-5139. doi:10.1200/JCO.2010.29.7101

3. Fizazi K, Carducci M, Smith M, Damião R, Brown J, Karsh L, Milecki P, Shore N, Rader M, Wang H, Jiang Q, Tadros S, Dansey R, Goessl C (2011) Denosumab versus zoledronic acid for treatment of bone metastases in men with castration-resistant prostate cancer: a randomised, double-blind study. Lancet 377: 813-822. doi:10.1016/S0140-6736(10)62344-6

4. Bamias A, Kastritis E, Bamia C, Moulopoulos LA, Melakopoulos I, Bozas G, Koutsoukou V, Gika D, Anagnostopoulos A, Papadimitriou C, Terpos E, Dimopoulos MA (2005) Osteonecrosis of the jaw in cancer after treatment with bisphosphonates: incidence and risk factors. J Clin Oncol 23: 8580-8587

5. Badros A, Weikel D, Salama A, Goloubeva O, Schneider A, Rapoport A, Fenton R, Gahres N, Sausville E, Ord R, Meiller T (2006) Osteonecrosis of the jaw in multiple myeloma patients: clinical features and risk factors. J Clin Oncol 24:945-952

6. Ripamonti CI, Maniezzo M, Campa T, Fagnoni E, Brunelli C, Saibene G, Bareggi C, Ascani L, Cislaghi E (2008) Decreased occurrence of osteonecrosis of the jaw after implementation of dental preventive measures in solid tumour patients with bone metastases treated with bisphosphonates. the experience of the National Cancer Institute of Milan. Ann Oncol 20:137-145. doi:10.1093/ annonc/mdn526

7. Vahtsevanos K, Kyrgidis A, Verrou E, Katodritou E, Triaridis S, Andreadis CG, Boukovinas I, Koloutsos GE, Teleioudis Z, Kitikidou K, Paraskevopoulos P, Zervas K, Antoniades K (2009) Longitudinal cohort study of risk factors in cancer patients of bisphosphonate-related osteonecrosis of the jaw. J Clin Oncol 27: 5356-5362. doi:10.1200/JCO.2009.21.9584

8. Bozas G, Allgar V, Greenwood G, et al (2011). Osteonecrosis of the jaw in patients treated with sunitinib and zoledronic acid (abstract e15116). J Clin Oncol. Available at: http://meetinglibrary.asco.org/ content/82466-102.

9. Smidt-Hansen T, Folkmar TB, Fode K, Agerbaek M, Donskov F (2013) Combination of zoledronic acid and targeted therapy is active but may induce osteonecrosis of the jaw in patients with metastatic renal cell carcinoma. J Oral Maxillofac Surg 71:15321540. doi:10.1016/j.joms.2013.03.019

10. Saad F, Brown JE, Poznak CV, et al. (2012) Incidence, risk factors, and outcomes of osteonecrosis of the jaw: integrated analysis from three blinded active-controlled phase III trials in cancer patients with bone metastases. Ann Oncol 23:1341-1347. doi:10.1093/ annonc/mdr435

11. Advisory Task Force on Bisphosphonate-Related Ostenonecrosis of the Jaws, American Association of Oral and Maxillofacial Surgeons (2007) American Association of Oral and Maxillofacial Surgeons position paper on bisphosphonate-related osteonecrosis of the jaws. J Oral Maxillofac Surg 65(3):369-376

12. Junquera L, Gallego L (2008) Nonexposed bisphosphonate-related osteonecrosis of the jaws: another clinical variant? J Oral Maxillofac Surg 66:1516-1517. doi:10.1016/j.joms.2008.02.012

13. Ruggiero SL, Dodson TB, Assael LA, et al. (2009) American Association of Oral and Maxillofacial Surgeons position paper on bisphosphonate-related osteonecrosis of the jaws-2009 update. J Oral Maxillofac Surg 67(suppl 1):2-12

14. Colella G, Campisi G, Fusco V (2009) American Association of Oral and Maxillofacial Surgeons position paper: bisphosphonaterelated osteonecrosis of the jaws - 2009 update: the need to refine the BRONJ definition. J Oral Maxillofac Surg 67:2698-2699. doi: 10.1016/j.joms.2009.07.097

15. Otto S, Marx RE, Tröltzsch M, Ristow O, Ziebart T, Al-Nawas B, Groetz KA, Ehrenfeld M, Mercadante V, Porter S, Bedogni A, Campisi G, Fusco V, Dayisoylu E, Fliefel R, Herlofson BB, Pautke C, Kwon T-G, Fedele S (2015) Comments on "Diagnosis and Management of Osteonecrosis of the Jaw: a systematic review and international consensus”. J Bone Miner Res 30:1113-1115. doi:10.1002/jbmr.2525

16. Ruggiero SL, Dodson TB, Fantasia J, Goodday R, Aghaloo T, Mehrotra B, O'Ryan F (2014) American Association of Oral and Maxillofacial Surgeons. American Association of Oral and Maxillofacial Surgeons position paper on medication-related osteonecrosis of the jaw-20 14 update. J Oral Maxillofac Surg 72:1938-1956. doi:10.1016/j.joms.2014.04.031

17. Fusco V, Galassi C, Berruti A, Ciuffreda L, Ortega C, Ciccone G, Angeli A, Bertetto O (2011) Osteonecrosis of the jaw after zoledronic acid and denosumab treatment. J Clin Oncol 29(17):521-522. doi:10.1200/JCO.2011.35.1551 Epub 2011 May 2

18. Setabutr D, Hales NW, Krempl GA (2010) Necrotizing fasciitis secondary to bisphosphonate-induced osteonecrosis of the jaw. Am J Otolaryngol 31:127-129. doi:10.1016/j.amjoto.2008.11.002

19. Kaehling C, Streckbein P, Schmermund D, Henrich M, Burchert D, Gattenloehner S, Howaldt HP, Wilbrand JF (2014) Lethal cervical abscess following bisphosphonate related osteonecrosis of the jaw. J Craniomaxillofac Surg 42:1203-1206. doi:10.1016/j.jcms.2014. 02.009

20. Hillner BE, Ingle JN, Chlebowski RT, Gralow J, Yee GC, Janjan NA, Cauley JA, Blumenstein BA, Albain KS, Lipton A, Brown S (2003) American Society of Clinical Oncology. American Society of Clinical Oncology 2003 update on the role of bisphosphonates and bone health issues in women with breast cancer. J Clin Oncol 21:4042-4057

21. Berenson JR, Hillner BE, Kyle RA, et al. (2002) American Society of Clinical Oncology Clinical Practice Guidelines: the role of bisphosphonates in multiple myeloma. J Clin Oncol 20:3719-3736

22. Lacy MQ, Dispenzieri A, Gertz MA, Greipp PR, Gollbach KL, Hayman SR, Kumar S, Lust JA, Rajkumar SV, Russell SJ, Witzig TE, Zeldenrust SR, Dingli D, Bergsagel PL, Fonseca R, Reeder CB, Stewart AK, Roy V, Dalton RJ, Carr AB, Kademani D, Keller EE, Viozzi CF, Kyle RA (2006) Mayo clinic consensus statement for the use of bisphosphonates in multiple myeloma. Mayo Clin Proc 81:1047-1053 
23. Kyle RA, Yee GC, Somerfield MR, Flynn PJ, Halabi S, Jagannath S, Orlowski RZ, Roodman DG, Twilde P, Anderson K (2007) American Society of Clinical Oncology. American Society of Clinical Oncology 2007 clinical practice guideline update on the role of bisphosphonates in multiple myeloma. J Clin Oncol 25: 2464-2472

24. Durie BG (2007) Use of bisphosphonates in multiple myeloma: IMWG response to Mayo Clinic consensus statement. Mayo Clin Proc 82:516-517

25. Aapro M, Abrahamsson PA, Body JJ, Coleman RE, Colomer R, Costa L, Crinò L, Dirix L, Gnant M, Gralow J, Hadji P, Hortobagyi
GN, Jonat W, Lipton A, Monnier A, Paterson AH, Rizzoli R, Saad F, Thürlimann B (2008) Guidance on the use of bisphosphonates in solid tumours: recommendations of an international expert panel. Ann Oncol 19:420-432

26. Van Poznak CH, Temin S, Yee GC, Janjan NA, Barlow BE, Biermann JS, Bosserman LD, Geoghegan C, Hillner BE, Theriault RL, Zuckerman DS, Van Roenn JH (2011) American Society of Clinical Oncology. American Society of Clinical Oncology executive summary of the clinical practice guideline update on the role of bone-modifying agents in metastatic breast cancer. J Clin Oncol 29:1221-1227. doi:10.1200/JCO.2010.32.5209 